Georgia State University

ScholarWorks @ Georgia State University

$12-21-2020$

\title{
Trans Men's Access to Knowledgeable Providers and Their Experiences in Health Care Settings: Differences by Demographics, Mental Health, and Degree of Being "Out" to Providers
}

\author{
Kristie L. Seelman \\ Georgia State University, kseelman@gsu.edu \\ Shanna K. Kattari \\ The University Of Michigan, skattari@umich.edu \\ Penny Harvey \\ Georgia State University, pharvey5@gsu.edu \\ Matthew Bakko \\ The University Of Michigan, mbakko@umich.edu
}

Follow this and additional works at: https://scholarworks.gsu.edu/ssw_facpub

Part of the Gender and Sexuality Commons, Medicine and Health Commons, and the Social Work Commons

\section{Recommended Citation}

Seelman, Kristie L.; Kattari, Shanna K.; Harvey, Penny; and Bakko, Matthew, "Trans Men's Access to Knowledgeable Providers and Their Experiences in Health Care Settings: Differences by Demographics, Mental Health, and Degree of Being "Out" to Providers" (2020). SW Publications. 88.

doi: https://doi.org/10.1093/hsw/hlaa030

This Article is brought to you for free and open access by the School of Social Work at ScholarWorks @ Georgia State University. It has been accepted for inclusion in SW Publications by an authorized administrator of ScholarWorks @ Georgia State University. For more information, please contact scholarworks@gsu.edu. 
Running head: Trans Men's Health Care

Trans Men's Access to Knowledgeable Providers and Experiences in Health Care Settings: Differences by Demographics, Mental Health, and Degree of Being “Out” to Providers

Kristie L. Seelman, PhD, MSW, Associate Professor, School of Social Work, Georgia State University Shanna K. Kattari, PhD, MEd, Assistant Professor, School of Social Work, University of Michigan Penny Harvey, MA, Doctoral Student, Department of Sociology, Georgia State University Matthew Bakko, MSW, MA, Doctoral Student, School of Social Work and Department of Sociology, University of Michigan

This is a post-print of an article published within Health \& Social Work and available at https://doi.org/10.1093/hsw/hlaa030

\section{Author Note}

Correspondence concerning this article should be addressed to Kristie Seelman, School of Social Work, Georgia State University, PO Box 3992, Atlanta GA 30302-3992. Phone: (404) 413-1071. E-mail: kseelman@gsu.edu 


\begin{abstract}
Transgender adults face a health care system rife with stigma, including a lack of culturally responsive providers and high likelihood of discrimination and mistreatment. However, there is a gap in knowledge about trans men - those assigned a female sex at birth who identify as men or as transmasculine - including subgroups such as trans men of color. Using data from the U.S. Transgender Survey - the largest transgender survey conducted in the United States - this study analyzes whether trans men's access to knowledgeable providers and experiences of mistreatment in health care were related to demographic and mental health characteristics and degree of being “out” to providers. Among 7,950 trans men, respondent race/ethnicity, education level, disability status, psychological distress, suicidality, and being less “out” were associated with assessing one's health care provider as not knowledgeable about trans-related care. Mistreatment in health care was more common among Alaska Native/American Indian trans men; those who lived in or near poverty; those who were queer, pansexual, bisexual, or an orientation not listed; those with a disability; those experiencing distress or suicidality, and those who were more "out." This article discusses how findings can inform culturally responsive health care interventions with trans men.
\end{abstract}

Keywords: transgender; trans men; health care; discrimination; mental health 
When attempting to access health care, transgender and nonbinary (trans/NB) individuals, including transgender men (those assigned a female sex at birth who identify as men or as transmasculine), face a severe lack of knowledgeable providers, rampant transphobia and mistreatment, and other barriers to care (James et al., 2016). Yet, less is known about how experiences in health care and access to knowledgeable providers may differ among subgroups of trans/NB individuals, including among subgroups of trans men, such as trans men of color. This study examines this topic, using data from the 2015 U.S. Transgender Survey (USTS).

\section{Lack of Knowledgeable and Culturally Responsive Providers}

Few health care providers are adequately prepared for providing trans-affirming care (Obedin-Maliver et al., 2011). "Informational erasure" means that practitioners and patients often assume that knowledge is simply not available about how to best serve this population (Lombardi, 2001). Since there are a diversity of experiences and needs among trans/NB people, the traditional "one-size-fits-all" model of health care is often not appropriate (Bauer et al., 2009). For example, trans men may need services often thought of as "women services," such as pap smears or birth control, but the normalization of cisgender (non-transgender) and binary identities in health care materials and assumptions about what patients will look like or need act as barriers. Due to the lack of institutional knowledge and provider training, trans/NB patients are often burdened with educating providers about trans health care and many cannot or choose not to access health care due to the dearth of knowledgeable providers (James et al., 2016).

\section{Transphobia and Mistreatment in Health Care}

Transphobia and mistreatment are rampant for trans/NB people in health care. According to the USTS, about $33 \%$ of trans/NB people (and $42 \%$ of trans men) had a negative health care experience in the past year (James et al., 2016) such as being asked invasive questions, being 
denied health care, and being misgendered (addressed with pronouns, names, or gendered terms that do not match one's identity; James et al., 2016). Discrimination is further elevated for trans/NB people of color and those with disabilities (Author, 2015, 2016a; James et al., 2016). Analysis of national data from 2008-2009 identified certain "female-to-male" individuals as being more likely to experience health care discrimination, including: those who were Native American or multiracial; those with a graduate degree; those who were queer, asexual, or "other" sexual orientation; those with yearly income over $\$ 60,000$, and those aged 45 years or younger (Shires \& Jaffee, 2015). Additionally, the more "out" and/or visible someone is as transgender, the more likely they are to experience discrimination in health care settings (Author, 2016b).

\section{Consequences of Poor Health Care}

Experiencing transgender discrimination in health care is associated with mental health struggles and substance use for coping (Clements-Nolle, Marx, \& Katz, 2006; Reisner et al., 2015), and fear of accessing health services was found to significantly mediate the relationship between gender identity (being transgender vs. cisgender) and physical health, disability, depressive symptomatology, and perceived stress among LGBT adults age 50 and older (Fredriksen-Goldsen et al., 2014). Trans/NB individuals may delay seeking needed medical care due to concerns about discrimination from providers, which has been associated with poorer mental health (Author, 2017). Trans women under a physician's care are more likely than peers without a provider to engage with risk reduction behaviors, such as obtaining needles from a doctor (Sanchez, Sanchez, \& Danoff, 2009), and those who access transition-related care have lower risks for suicidal ideation, non-injection drug use, and binge drinking (Wilson et al., 2015). In order to promote improved health for trans/NB people, social workers need to challenge the 
policies and culture of health care systems that permit provider ignorance, discrimination, and poor quality care for this population (Lewis, 2017; Wheeler \& Dodd, 2011).

\section{Current Study}

Much is known about health care-related stigma for trans/NB people, the lack of culturally responsive care, and ways that quality of care differs across subgroups; yet, there is less evidence about trans men’s experiences. Although a past study (Shires \& Jaffee, 2015) assessed health care discrimination among "female-to-male" subgroups, this study did not look at types of discrimination or perceptions of provider knowledge. The present study's research question is: Among trans men in the U.S., does access to knowledgeable health care providers and the likelihood of mistreatment in health care significantly vary by demographic and mental health characteristics and the degree to which one is "out" to providers as transgender?

\section{Methods}

The 2015 USTS was coordinated by the National Center for Transgender Equality (NCTE) to capture data about trans/NB adults' experiences across many sectors of life, such as employment, health care, and education (James et al., 2016). Recruitment was carried out by NCTE staff, an advisory committee, and a network of 400 organizational partners. The USTS was made available online, in English and Spanish, during 34 days in the summer of 2015. Participants $(N=27,715)$ identified as transgender, nonbinary, and genderqueer and were 18 or older. For additional information about methodology, see James et al. (2016). A de-identified USTS dataset was provided to the first author.

\section{Measures}

Filter variable. This analysis focuses on trans men, as categorized by the "gender5" variable. Participants were included if they indicated that their sex assigned at birth was female 
and that "trans man" was the best term for their current gender identity. A small number said their sex assigned at birth was male and current identity was trans man but had been grouped with trans men by the NCTE research team based upon other survey responses (NCTE, 2017).

Health care-related variables. Participants were asked to assess providers' knowledge about trans people: Thinking about the doctor or provider you go to for your trans-related health care (such as hormone treatment), how much do they know about providing health care for trans people? Four response options ranged from "Know almost nothing" to "Know almost everything." Using the same response options, another question asked about routine provider knowledge: How much does your routine health care provider (who you see for physicals, flu, diabetes, etc.) know about health care for trans people? Those with the same provider for both types of care had their response from the first question copied into the second question. Those without such providers or who answered "I am not sure" were removed from analyses.

Participants were asked about mistreatment in health care in the past year: In the past year, did you have any of these things happen to you, as a trans person, when you went to see a doctor or health care provider? A series of items were then provided, with "Yes" and "No" response options for each: (a) had to teach a doctor about trans care; (b) doctor refused to give trans-related care; (c) doctor refused to give other health care; (d) doctor asked invasive questions; (e) doctor used harsh/abusive language; (f) doctor was physically rough/abusive; (g) was verbally harassed in health care setting; (h) was physically attacked in health care setting; and (i) unwanted sexual contact in health care setting. Those who did not see a provider in the past year were skipped past these questions. We created a composite health care mistreatment variable to indicate whether participants experienced any of the above forms of mistreatment. 
Demographic and mental health variables. Participants were asked: Please select the choice that most accurately describes your racial/ethnic identity (Check all that apply). The original question offered 10 options; we used a recoded version of this variable provided by NCTE that had condensed responses into seven categories: "Alaska Native/American Indian alone," “Asian/Asian American/Native Hawaiian/Pacific Islander alone," "Biracial/multiracial/ not listed," "Black/African American alone," "Latino/a/Hispanic alone," "White alone," and “Middle Eastern/North African alone." Poverty status was calculated by the NCTE survey team with a dichotomous (yes/no) variable called poverty based upon multiple questions related to family size, age of householder, and income compared to the U.S. Census Bureau's official poverty measure (NCTE, 2017), indicating whether each participant was living in or near poverty. For education, participants were asked: What is the highest level of school or degree you have completed? We use a recoded variable, education4, which includes four simplified response options: "Less than high school," "High school grad (including GED)," "Some college (no degree)/Associate's," and "Bachelor's degree or higher." The survey question related to sexual orientation was worded: What best describes your sexual orientation? We chose a condensed recode of this variable, $q 2 \_8 c a t 7$, that had the following categories: "Asexual," "Bisexual," “Gay/lesbian/same-gender loving," "Heterosexual/straight," "Pansexual," "Queer,” and "A sexual orientation not listed above.” Disability status was captured as a dichotomous variable (yes/no) based on the question: Do YOU identify as a person with a disability?

Serious psychological distress was measured using the Kessler Psychological Distress Scale's (K6) six items related to symptoms of distress in the past 30 days (e.g., During the past 30 days, how often did you feel that everything was an effort?). Response options include: “All of the time," "Most of the time," "Some of the time," "A little of the time," and "None of the 
time." We used the recoded version of this variable, kessler6cat, that was a dichotomous indictor of whether someone had experienced serious psychological distress, indicated by a K6 score of 13 or above (yes/no). We used two variables related to suicide: lifetime suicidal thoughts and lifetime suicide attempt. Two questions were used by the USTS research team to construct a lifetime suicidal thoughts variable, suicidethoughts: (1) At any time in the past 12 months did you seriously think about trying to kill yourself?; and (2) At any time in your life, have you seriously thought about trying to kill yourself? Those answering "yes" to either question were categorized as having lifetime suicidal thoughts. The variable suicideattempt, was constructed by the NCTE research team based upon participant responses to two questions: (1) During the past 12 months, did you try to kill yourself?; and (2) At any time in your life, did you try to kill yourself? A "yes" to either question was considered an indication of lifetime suicide attempt. Those who reported no lifetime suicidal ideation were not asked these questions and coded as not attempting suicide.

“Outness" to health care providers. Participants were asked: How many people in each group below currently know you are trans? One of the groups listed was Current Health Care Providers. Response options included "I currently have no people like this in my life," "All know that I am trans," "Most know that I am trans," "Some know that I am trans," and "None know that I am trans." Those who said they had no such people were dropped from analyses.

\section{Data Analysis}

Using SPSS version 24, we examined whether the perceived knowledge of health care providers about trans-related care and experiences of mistreatment in health care were associated with respondents' demographic characteristics, mental health, and "outness." Data were analyzed for associations between variables using chi-squares. If significant differences were detected and at least one of the variables being compared had more than two response options, a z-test was 
used to compare column proportions to determine which categories were significantly different from one another (e.g., queer vs. pansexual, queer vs. heterosexual, etc.), adjusting $p$-values using the Bonferroni method.

\section{Results}

The analytic sample included 7,950 trans men, ranging in age from 18-73, with a median age of 25. Table 1 provides an overview of descriptive statistics for the variables of interest. | Insert Table 1 here |

\section{Health Care Provider's Knowledge about Transgender Health Needs}

Among this sample of trans men, 69.9\% $(n=5,552)$ reported having a trans-specific health care provider and $77.6 \%(n=6,166)$ reported having a routine health care provider.

Trans-specific health care provider. Trans-specific provider knowledge was significantly related to participant race/ethnicity $\left(\chi^{2}(18)=68.77, p<.001\right)$ and education $\left(\chi^{2}(9)=\right.$ 36.85, $p<.001$; tables available by request). Bi/Multiracial and Latino trans men were less likely to evaluate their provider as knowledgeable about providing health care to trans people than were White trans men; meanwhile, Black trans men were more likely to say their provider "knows most things" compared to Bi/Multiracial, White, or Middle Eastern/North African trans men. Trans men with less than a college degree were more likely to say their provider "knows almost everything" about providing health care for trans people than were trans men with a college degree or higher. Trans men with a disability $\left(\chi^{2}(3)=20.73, p<.001\right)$, those experiencing serious psychological distress $\left(\chi^{2}(3)=49.46, p<.001\right)$, and those with a lifetime suicide attempt $\left(\chi^{2}(3)=26.99, p<.001\right)$ were more likely to say their provider "knows almost nothing" compared to trans men without these characteristics or conditions. With regard to "outness," a 
significantly greater proportion of those who said their trans-specific provider "knows almost everything" were also out to all providers than would occur by chance $\left(\chi^{2}(9)=80.76, p<.001\right)$.

Routine health care provider. Routine health care provider knowledge was significantly related to participant race/ethnicity $\left(\chi^{2}(18)=60.83, p<.001\right)$, poverty status $\left(\chi^{2}(3)=35.2, p<\right.$ $.001)$, education $\left(\chi^{2}(9)=148.10, p<.001\right)$, sexual orientation $\left(\chi^{2}(18)=119.26, p<.001\right)$, and disability $\left(\chi^{2}(3)=43.82, p<.001\right.$; tables available by request $) . \mathrm{Bi} /$ Multiracial and White trans men were more likely to evaluate their routine provider as being less knowledgeable compared to Black trans men and Latino trans men, and Asian/Native Hawaiian/Pacific Islander trans men were less likely than Black trans men to say their provider "knows almost everything." Trans men living in or near poverty, those with a high school diploma/GED or some college, those who were asexual or pansexual, and those with a disability were less likely to say their provider was knowledgeable compared to those with greater income or education, other orientation groups, and those without a disability. Those with a sexual orientation not listed were less likely to say their provider "knows almost everything" versus heterosexual or queer trans men. Trans men experiencing serious psychological distress $\left(\chi^{2}(3)=170.46, p<.001\right)$ or who had a history of lifetime suicidal thoughts $\left(\chi^{2}(3)=48.23, p<.001\right)$ or a suicide attempt $\left(\chi^{2}(3)=46.81, p<.001\right)$ were more likely to say their routine health care provider "knows almost nothing" about transrelated care compared to trans men without these risk factors. A significantly greater proportion of those who said their trans-specific provider "knows almost everything" were out to all providers than would occur by chance $\left(\chi^{2}(9)=415.31, p<.001\right)$.

\section{Mistreatment in Health Care Settings}

Various forms of mistreatment were associated with participant race/ethnicity, poverty status, education, and sexual orientation (tables available by request). Trans men with a 
disability, those experiencing psychological distress, and those who had attempted suicide were more likely to experience health care mistreatment compared to trans men without each of these conditions (see Table 2). Trans men with suicidal thoughts were more likely to experience health care mistreatment than trans men without suicidal thoughts, except for experiencing physical attacks, which had too few cases to compute accurate estimates. Being more "out" to health care providers was generally associated with greater likelihood of mistreatment in health care.

| Insert Table 2 approximately here |

Alaska Native/American Indian trans men, compared to all or some of the other race/ethnicity groups, reported significantly greater likelihood of having to teach a doctor about trans care $\left(\chi^{2}(6)=23.2, p<.001\right)$, being verbally harassed $\left(\chi^{2}(6)=46.1, p<.001\right)$, having a doctor who refused to give other health care $\left(\chi^{2}(6)=19.25, p<.01\right)$, being asked invasive questions $\left(\chi^{2}(6)=21.54, p<.01\right)$, and having a doctor who used harsh or abusive language $\left(\chi^{2}(6)\right.$ $=29.03, p<.001)$. They were more likely to experience any form of mistreatment in health care compared to all other groups except Middle Eastern/North African trans men $\left(\chi^{2}(6)=30.05, p<\right.$ .001). Trans men of color (other than those who were Latino alone) were more likely to experience a doctor being physically rough or abusive compared to White or Latino trans men $\left(\chi^{2}(3)=19.99, p<.001\right)$. Bi/Multiracial trans men and trans men of a race not listed were more likely to have experienced unwanted sexual contact in a health care setting compared all other groups $\left(\chi^{2}(2)=14.83, p<.001\right)$.

Trans men living in or near the poverty level were more likely to say that a doctor refused to give them trans-related care $\left(\chi^{2}(1)=16.59, p<.001\right)$, refused to give them other health care $\left(\chi^{2}(1)=14.28, p<.001\right)$, asked invasive questions $\left(\chi^{2}(1)=9.85, p<.01\right)$, used harsh or abusive language $\left(\chi^{2}(1)=17.91, p<.001\right)$, or was physically rough or abusive $\left(\chi^{2}(1)=12.92, p<.001\right)$. 
They were also more likely to say they were verbally harassed $\left(\chi^{2}(1)=26.48, p<.001\right)$ or physically attacked in a health care setting $\left(\chi^{2}(1)=7.78, p<.01\right)$ or to have experienced any health care mistreatment $\left(\chi^{2}(1)=5.04, p<.05\right)$. Trans men with greater education (at least some college) were more likely to say that they had to teach a doctor about trans care $\left(\chi^{2}(3)=63.8, p<\right.$ $.001)$, and those with a bachelor's degree were more likely to be asked invasive questions $\left(\chi^{2}(3)\right.$ $=33.35, p<.001)$. Trans men with a bachelor's degree were more likely than all other groups to experience any form of health care mistreatment $\left(\chi^{2}(3)=59.89, p<.001\right)$.

Trans men who were queer were at greater risk for mistreatment in health care, while asexual and straight trans men had some of the lowest risk. Compared to most or all other groups, queer trans men were more likely to have to teach a doctor about trans issues $\left(\chi^{2}(6)=\right.$ $75.47, p<.001)$, be asked invasive questions $\left(\chi^{2}(6)=80.24, p<.001\right)$, and experience any mistreatment $\left(\chi^{2}(6)=78.7, p<.001\right)$. Asexual trans men were less likely to have to teach a doctor about trans issues (compared to all others except heterosexuals and those with an orientation not listed, $\chi^{2}(6)=75.47, p<.001$ ), be asked invasive questions (compared to bisexuals and pansexuals, $\chi^{2}(6)=80.24, p<.001$ ), and have a doctor use harsh or abusive language (compared to those with an orientation not listed, $\chi^{2}(6)=20.04, p<.01$ ). Heterosexuals were less likely than bisexuals and pansexuals to be asked invasive questions $\left(\chi^{2}(6)=80.24, p<\right.$ $.001)$ and less likely to have a doctor use harsh or abusive language compared to trans men who identified with a sexual orientation not listed $\left(\chi^{2}(6)=20.04, p<.01\right)$. Greater proportions of trans men who were out to "all" and/or "most" providers said they had to teach a doctor about trans care $\left(\chi^{2}(3)=341.55, p<.001\right)$, had a doctor who refused to give trans-related care $\left(\chi^{2}(3)=\right.$ $32.23, p<.001)$, had a doctor who asked invasive questions $\left(\chi^{2}(3)=150.36, p<.001\right)$, or had a doctor who used harsh or abusive language $\left(\chi^{2}(3)=19.3, p<.001\right)$. They were also more likely 
to have been verbally harassed in a health care setting $\left(\chi^{2}(3)=22.41, p<.001\right)$ or to experience any of the forms of mistreatment in health care $\left(\chi^{2}(3)=365.3, p<.001\right)$. The other forms of mistreatment did not show a significant relationship to being out to providers.

\section{Discussion}

Notably, three out of 10 trans men in this sample either could not find or did not seek out a health provider for trans-related care. One reason for not seeking such care might be the lack of culturally responsive providers. Additionally, about $22 \%$ of trans men reported not having a provider for routine health care; in comparison, about $17 \%$ of U.S. adults age 18-64 did not have a usual source of health care in 2015-2016 (Centers for Disease Control and Prevention [CDC], 2017). Of note, the percentage among trans men is nearly identical to that of the overall male population $(21 \%)(\mathrm{CDC}, 2017)$, suggesting that masculine norms about help-seeking may be one potential barrier to seeking care. Findings also document a lack of knowledge among providers, with over $27 \%$ of those with a trans-specific provider and $54 \%$ of those with a routine provider saying that this provider knows very little ("nothing" or "some things") about trans-related care.

Subgroups of trans men most at risk for lacking access to a knowledgeable provider for trans-specific care include: Bi/Multiracial and Latino trans men; those with a disability; those experiencing psychological distress or with a past suicide attempt; and those who are less "out." These groups could benefit from targeted interventions to increase access to knowledgeable providers. Findings about mental health may indicate that lack of access to a knowledgeable provider impacts a patient's mental health, or that patients with mental health struggles are more likely to evaluate their provider negatively; these relationships are worth future research. Findings regarding education level - that trans men with a college degree or higher are less likely to have access to a knowledgeable provider for trans-related care - may be reflective of how 
education level may intersect with how much a patient knows about trans health care and is willing to critically assess their provider. With regard to "outness," perhaps those who perceive their trans-specific health care providers as more knowledgeable are therefore able to be "out" safely. Alternatively, those who are more "out" may have greater access to or put greater effort into finding knowledgeable providers, both for routine and trans-specific care.

Those most likely to say their routine provider is not knowledge about trans care included Bi/Multiracial and White trans men; those living in/near poverty; those with less education; those who were asexual, pansexual, or a sexual orientation not listed; those with a disability; those experiencing serious psychological distress; those with lifetime suicidal ideation or a suicide attempt; and those who were less "out." Nearly all of these groups are likely to experience other barriers to health care, such as discrimination based upon race. Such intersectional considerations are incredibly important for social workers and other health professionals to consider in efforts to improve primary care providers' abilities to serve trans men and address health disparities (Wheeler \& Dodd, 2011). It is less clear why White trans men - who would generally be thought to have greater access to routine health care- are evaluating their provider as less knowledgeable. One possibility is that if White trans men are more likely than other groups to live in a rural area, they may have fewer providers to choose from who are generally less culturally responsive.

The most common forms of mistreatment in health care were having to teach a doctor about trans care (32\%), having a doctor ask invasive questions (21\%), and having a doctor who refused to provide trans-related care (10\%). When compared to the overall USTS sample (at $24 \%, 15 \%$, and $8 \%$ ), trans men experienced these occurrences at higher rates. This suggests that the experiences of trans men in seeking health care differ in a unique way from others within the trans/NB population. 
Alaska Native/Native American trans men are at striking risk across categories of mistreatment in health care, in line with an earlier study (Shires \& Jaffee, 2015). There is little research about this group of trans/NB people even though they are particularly impacted by colonialist violence against their culture(s), including hegemonic erasure of indigenous societal norms that have recognized and celebrated gender diversity such as Two-Spirit identities (Walters, Evans-Campbell, Simoni, Ronquillo, \& Bhuyan, 2006). Further, certain groups of men of color or of races not listed were more likely than White trans men to experience the most blatant forms of violence, such as having a doctor who was physically abusive. There is a need for interventions against such violence targeting not only an interpersonal level (e.g., identifying and stopping abuse) but also at the structural level (e.g., policies for reporting abuse) and individual level (e.g., resilience-building strategies among trans men).

In line with past research (Shires \& Jaffee, 2015), trans men with greater education were more likely to say they experienced health care mistreatment; they were more likely to have a doctor turn to them as an expert - either being asked to educate or being asked invasive questions. Perhaps providers, when feeling unprepared, are more likely to turn to patients perceived as "well-educated" for information. Similarly, queer trans men also reported greater likelihood that they have been asked inappropriate questions, while asexual and straight trans men generally had a lower likelihood. Providers who are less knowledgeable about queer, pansexual, and bisexual identities may be turning to patients for information about these identities, instead of seeking professional training on such identities. When encountering an asexual patient, sexuality may never come up or may not solicit curiosity from the provider. Trans men who are heterosexual, meanwhile, may benefit from a "normalizing" lens from providers, therefore not being subject to the same follow-up questions. Trainings on trans health 
care need to emphasize that patients should not be relied upon to "educate" providers. Other groups at risk for mistreatment included trans men living in/near poverty (in contrast to past research; see Shires \& Jaffee, 2015), those with disabilities, those with distress or suicidality, and those who are more "out" (in line with past research about "outness" and experiences of stigma; see Bockting et al., 2013). As stated earlier, such groups face intersectional forms of oppression; mistreatment from providers likely adds additional strain and stress to their lives.

\section{Implications}

As articulated by the NASW (2016), social workers employed in health care have a professional and ethical commitment to advocate with and on behalf of clients from marginalized populations to improve the health care system, promote patient health, and ensure access to quality care. For trans/NB patients, this means challenging a lack of culturally responsive care and transphobic systemic norms (Lewis, 2017). Increasing knowledge and skills among routine health care providers is particularly important to help encourage trans men to seek access to preventative and routine care. Given that some negative experiences in health care are heightened for queer, bisexual, and pansexual trans men, efforts to increase provider knowledge should incorporate information about sexual orientation.

Not surprisingly, mistreatment in health care particularly impacts some of the most vulnerable groups of trans men, such as trans men of color and those living in poverty; this suggests the importance of targeting efforts to improve trans men's health care within areas with high concentrations of people of color (including via Indian Health Services and in metropolitan areas) and people living in poverty (such as through health clinics). Additionally, there were consistent associations between lack of access to knowledgeable providers or mistreatment in health care and mental health. Future research should further examine this link. Finally, the 
association between being "out" to providers and mistreatment in health care is one of the clearest indications of transgender discrimination at work; continued efforts are needed to challenge transphobia in health care, from the subtle to the more blatant forms of abuse.

\section{Limitations}

This study analyzed data from a one-time, online survey with a convenience sample. Findings should not be generalized to all trans men, especially those less connected to community organizations and those who do not read English or Spanish. We were only able to analyze data about provider knowledge for those who said they had a provider and about mistreatment for those who had seen a doctor in the past year; those not meeting these conditions were skipped past these questions by the survey design. Future research should investigate the characteristics of trans/NB adults who do not have a consistent provider or are not seeking health care. Additionally, we do not know the type of health setting in which experiences of mistreatment occurred or how commonly such incidents happen across the life span, as queries focused on incidents within the past year. Further, our analysis only used bivariate statistics. Future research could investigate multivariate models, controlling for other factors that may influence health care experiences. Relatedly, while we examined the relationship of race/ethnicity to perceived provider knowledge and mistreatment in health care, trans men of color with other marginalized identities (e.g., living in poverty) may experience additive or compounded risks related to provider knowledge or mistreatment; such lines of intersectional inquiry would be highly valuable in future research with trans/NB people. The USTS dataset we analyzed did not include data about whether participants lived in a rural, suburban, or urban area; such information should be examined in future research. Finally, this study focused on trans 
men. Other research is needed to document the experiences of trans women and nonbinary individuals, as well as trans/NB children and older adults.

\section{Conclusion}

The purpose of this study was to examine trans men's access to competent care and experiences in health care by demographics and mental health factors to help inform future efforts to increase provider competency and improve health care for this population. Findings indicate how the intersection of multiple forms of marginalization impact trans men's access to health care, demonstrating the need to educate providers about multiple forms of diversity and to create interventions aimed at improving care for trans men who are impacted by more than one type of oppression within health care systems. 


\section{References}

Bauer, G. R., Hammond, R., Travers, R., Kaay, M., Hohenadel, K. M., \& Boyce, M. (2009). “I don't think this is theoretical; This is our lives": How erasure impacts health care for transgender people. Journal of the Association of Nurses in AIDS Care, 20(5), 348-361. https://doi.org/10.1016/j.jana.2009.07.004

Bockting, W. O., Miner, M. H., Swinburne Romine, R. E., Hamilton, A., \& Coleman, E. (2013). Stigma, mental health, and resilience in an online sample of the US transgender population. American Journal of Public Health, 103(5), 943-951. https://doi.org/10.2105/AJPH.2013.301241

Centers for Disease Control and Prevention. (2017). Table 62. No usual source of health care among adults aged 18-64, by selected characteristics: United States, average annual, selected years 1993-1994 through 2015-2016. Retrieved from https://www.cdc.gov/nchs/data/hus/2017/062.pdf

Clements-Nolle, K., Marx, R., \& Katz, M. (2006). Attempted suicide among transgender persons: The influence of gender-based discrimination and victimization. Journal of Homosexuality, 51(3), 53-69. https://doi.org/10.1300/J082v51n03_04

Fredriksen-Goldsen, K. I., Cook-Daniels, L., Kim, H.-J., Erosheva, E. A., Emlet, C. A., HoyEllis, C. P., ... Muraco, A. (2014). Physical and mental health of transgender older adults: An at-risk and underserved population. Gerontologist, 54(3), 488-500. https://doi.org/10.1093/geront/gnt021

Harvard Medical School. (n.d.). National Comorbidity Survey: K10 and K6 Scales. Retrieved from https://www.hcp.med.harvard.edu/ncs/k6_scales.php

James, S. E., Herman, J. L., Rankin, S., Keisling, M., Mottet, L., \& Anafi, M. (2016). The report 
of the 2015 U.S. transgender survey. Washington, D.C. Retrieved from https://www.transequality.org/sites/default/files/docs/USTS-Full-Report-FINAL.PDF

Kattari, S. K., \& Hasche, L. (2016). Differences across age groups in transgender and gender non-conforming people's experiences of health care discrimination, harassment, and victimization. Journal of Aging and Health, 28(2), 285-306. doi:

$10.1177 / 0898264315590228$

Kattari, S. K., Walls, N. E., Speer, S. R., \& Kattari, L. (2016). Exploring the relationship between transgender-inclusive providers and mental health outcomes among transgender/gender variant people. Social Work in Health Care, 55(8), 1-16. doi: $10.1080 / 00981389.2016 .1193099$

Kattari, S. K., Walls, N. E., Whitfield, D. L., \& Langenderfer-Magruder, L. (2015). Racial and ethnic differences in experiences of discrimination in accessing health services among transgender people in the United States. International Journal of Transgenderism, 16(2), 68-79. doi: 10.1080/15532739.2015.1064336

Lewis, C. P. (2017). The road to trans-inclusive health care: Policy implications and the critical role of social work. Health \& Social Work, 42(1), 60-62. doi: 10.1093/hsw/hlw056

Lombardi, E. L. (2001). Enhancing transgender health care. American Journal of Public Health, 91(6), 869-872.

National Association of Social Workers. (2016). Social Work Practice in Health Care Settings. Retrieved from https://www.socialworkers.org/LinkClick.aspx?fileticket=fFnsRHX4HE\%3D\&portalid $=0$

National Center for Transgender Equality. (2017). 2015 U.S. Transgender Survey: Codebook. Washington, DC. 
Obedin-Maliver, J., Goldsmith, E. S., Stewart, L., White, W., Tran, E., Brenman, S., ... Lunn, M. R. (2011). Lesbian, gay, bisexual, and transgender-related content in undergraduate medical education. JAMA : Journal of the American Medical Association, 306(9), 971-977. https://doi.org/10.1001/jama.2011.1255

Reisner, S. L., Pardo, S. T., Gamarel, K. E., White Hughto, J. M., Pardee, D. J., \& Keo-Meier, C. L. (2015). Substance use to cope with stigma in healthcare among U.S. female-to-male trans masculine adults. LGBT Health, 2(4), 324-332. https://doi.org/10.1089/lgbt.2015.0001

Sanchez, N. F., Sanchez, J. P., \& Danoff, A. (2009). Health care utilization, barriers to care, and hormone usage among male-to-female transgender persons in New York City. American Journal of Public Health, 99(4), 713-719. doi: 10.2105/AJPH.2007.132035

Seelman, K. L., Colón-Diaz, M. J. P., LeCroix, R. H., Xavier-Brier, M., \& Kattari, L. (2017). Transgender noninclusive healthcare and delaying care because of fear: Connections to general health and mental health among transgender adults. Transgender Health, 2(1), 1728. doi: 10.1089/trgh.2016.0024

Shires, D. A., \& Jaffee, K. (2015). Factors associated with health care discrimination experiences among a national sample of female-to-male transgender individuals. Health \& Social Work, 1-8. https://doi.org/10.1093/hsw/hlv025

Walters, K. L., Evans-Campbell, T., Simoni, J. M., Ronquillo, T., \& Bhuyan, R. (2006). “My spirit in my heart": Identity experiences and challenges among American Indian and twospirit women. Journal of Lesbian Studies, 10(1), 125-149. doi: 10.1300/J155v10n01_07

Wheeler, D. P., \& Dodd, S.-J. (2011). LGBTQ capacity building in health. Health \& Social Work, 36(4), 307-310. https://doi.org/10.1093/hsw/36.4.307 
Wilson, E. C., Chen, Y., Arayasirikul, S., Wenzel, C., \& Raymond, H. F. (2015). Connecting the dots: Examining transgender women's utilization of transition-related medical care and associations with mental health, substance use, and HIV. Journal of Urban Health, 92(1), 182-192. doi: 10.1007/s11524-014-9921-4 
Table 1

Descriptive statistics for variables of interest among trans men $(\mathrm{N}=7,950)$

\begin{tabular}{|c|c|c|c|c|c|}
\hline \multicolumn{4}{|c|}{$\begin{array}{l}\text { Health Care Provider Knowledge \& Experiences of } \\
\text { Mistreatment in Health Care }\end{array}$} & \multicolumn{2}{|l|}{ Demographics } \\
\hline Variable & $\%(n)$ & Variable & $\%(n)$ & Variable & $\%(n)$ \\
\hline \multicolumn{2}{|c|}{ Trans-specific HCP knowledge } & \multicolumn{2}{|c|}{$\begin{array}{l}\text { Doctor asked invasive } \\
\text { questions }\end{array}$} & \multicolumn{2}{|l|}{ Race/ethnicity } \\
\hline Know almost nothing & $7.8(406)$ & Yes & $21.3(1509)$ & AK Native/AI & $1.4(109)$ \\
\hline Know some things & $20.2(1052)$ & No & $78.7(5584)$ & Asian/Native HI/PI & $2.6(207)$ \\
\hline Know most things & $29.4(1530)$ & \multicolumn{2}{|c|}{$\begin{array}{l}\text { Doctor used abusive } \\
\text { language }\end{array}$} & $\mathrm{Bi} / \mathrm{multiracial} / \mathrm{NL}$ & $6.1(481)$ \\
\hline $\begin{array}{l}\text { Know almost } \\
\text { everything }\end{array}$ & $42.6(2221)$ & Yes & 5.7 (406) & Black/African Amer. & $3.5(277)$ \\
\hline \multicolumn{2}{|l|}{ Routine HCP knowledge } & No & $94.3(6682)$ & Latino or Hispanic & $6.3(498)$ \\
\hline Know almost nothing & $26.1(1243)$ & \multicolumn{2}{|c|}{ Doctor rough/abusive } & White & $79.7(6334)$ \\
\hline Know some things & $28.2(1344)$ & Yes & $1.9(136)$ & Mid. East./North Afr. & $0.6(44)$ \\
\hline Know most things & $20.5(978)$ & No & $98.1(6952)$ & Living in/near poverty & \\
\hline $\begin{array}{l}\text { Know almost } \\
\text { everything }\end{array}$ & $25.2(1198)$ & \multicolumn{2}{|c|}{$\begin{array}{l}\text { Verbally harassed } \mathrm{HC} \\
\text { setting }\end{array}$} & Yes & $34.0(2567)$ \\
\hline \multicolumn{2}{|l|}{ Had to teach doctor } & Yes & $6.8(482)$ & No & $66.0(4977)$ \\
\hline Yes & $31.9(2259)$ & No & $93.2(6594)$ & Education & \\
\hline No & $68.1(4826)$ & \multicolumn{2}{|c|}{$\begin{array}{l}\text { Physically attacked } \mathrm{HC} \\
\text { setting }\end{array}$} & Less than high school & $3.5(278)$ \\
\hline \multicolumn{2}{|c|}{ Doctor refused trans-related care } & Yes & $0.4(31)$ & High school grad/GED & $13.8(1096)$ \\
\hline Yes & $10.2(722)$ & No & $99.6(7040)$ & Some college/Assoc. & $45.7(3636)$ \\
\hline No & $89.8(6362)$ & \multicolumn{2}{|c|}{$\begin{array}{l}\text { Unwanted sexual contact } \\
\text { HC setting }\end{array}$} & $\begin{array}{l}\text { Bachelor's degree or } \\
\text { higher }\end{array}$ & $37.0(2940)$ \\
\hline \multicolumn{2}{|c|}{ Doctor refused to give other care } & Yes & $1(72)$ & Sexual orientation & \\
\hline Yes & $3.2(230)$ & No & 99 (6998) & Asexual & $8.0(636)$ \\
\hline \multirow[t]{3}{*}{ No } & \multirow[t]{3}{*}{$96.8(6848)$} & \multicolumn{2}{|c|}{ Any negative experience } & Bisexual & $12.3(976)$ \\
\hline & & Yes & $42.6(2969)$ & Gay/lesbian/SGL & $12.8(1019)$ \\
\hline & & No & $57.4(4004)$ & Heterosexual/straight & $19.3(1535)$ \\
\hline \multicolumn{4}{|c|}{ Mental Health } & Pansexual & $17.8(1414)$ \\
\hline Variable & $\%(n)$ & Variable & $\%(n)$ & Queer & $24.4(1942)$ \\
\hline \multicolumn{2}{|c|}{ Serious psych. distress (current) } & \multicolumn{2}{|c|}{$\begin{array}{l}\text { Suicidal thoughts } \\
\text { (lifetime) }\end{array}$} & Not listed & $5.4(428)$ \\
\hline Yes & $36.6(2910)$ & Yes & $84.8(6740)$ & Disability status & \\
\hline \multirow[t]{7}{*}{ No } & $61.7(4907)$ & No & $15.1(1197)$ & Yes (has a disability) & $25.3(2007)$ \\
\hline & & \multicolumn{2}{|c|}{ Suicide attempt (lifetime) } & No & $74.7(5927)$ \\
\hline & & Yes & $44.3(3521)$ & Outness to HCP & \\
\hline & & No & $55.5(4414)$ & None know that I am trans & $16.2(1180)$ \\
\hline & & & & Some know that I am trans & $17.9(1307)$ \\
\hline & & & & Most know that I am trans & $18.5(1349)$ \\
\hline & & & & All know that I am trans & $47.4(3456)$ \\
\hline
\end{tabular}

Note. All health care mistreatment was in reference to the past year. All racial/ethnic groups are for those that reported that category alone, except for bi/multiracial. Abbreviations: $\mathrm{HCP}=$ health care provider; $\mathrm{HC}=$ health care; AK Native/AI = Alaskan Native/American Indian; Native HI = Native Hawaiian; PI = Pacific Islander; NL = not listed; African Amer. = African American; Mid. East./North Afr. = Middle Eastern/North African; Assoc. = Associate's degree; SGL = same-gender loving; Psych. = psychological. 
Table 2

Mistreatment in health care: Chi-square results for disability status and mental health variables

\begin{tabular}{|c|c|c|c|c|c|c|c|c|c|c|c|c|}
\hline & \multicolumn{3}{|c|}{ Disability Status } & \multicolumn{3}{|c|}{ Psychological Distress } & \multicolumn{3}{|c|}{ Suicidal Thoughts } & \multicolumn{3}{|c|}{ Suicide Attempt } \\
\hline & $\begin{array}{l}\text { Yes } \\
(\%)\end{array}$ & $\begin{array}{l}\text { No } \\
(\%)\end{array}$ & $\begin{array}{c}\chi^{2} \\
(d f=1)\end{array}$ & $\begin{array}{l}\text { Yes } \\
(\%)\end{array}$ & $\begin{array}{l}\text { No } \\
(\%)\end{array}$ & $\begin{array}{c}\chi^{2} \\
(d f=1)\end{array}$ & $\begin{array}{l}\text { Yes } \\
(\%)\end{array}$ & $\begin{array}{l}\text { No } \\
(\%)\end{array}$ & $\begin{array}{c}\chi^{2} \\
(d f=1)\end{array}$ & $\begin{array}{l}\text { Yes } \\
(\%)\end{array}$ & $\begin{array}{l}\text { No } \\
(\%)\end{array}$ & $\begin{array}{c}\chi^{2} \\
(d f=1)\end{array}$ \\
\hline \multicolumn{13}{|c|}{ Had to teach doctor } \\
\hline Yes & 39.1 & 29.5 & \multirow{2}{*}{$56.76 * * *$} & 33.7 & 30.8 & \multirow{2}{*}{$6.29 *$} & 33.2 & 25.0 & \multirow{2}{*}{$28.43 * * *$} & 37.4 & 27.5 & \multirow{2}{*}{$78.61 * * *$} \\
\hline No & 60.9 & 70.5 & & 66.3 & 69.2 & & 66.8 & 75.0 & & 62.6 & 72.5 & \\
\hline \multicolumn{13}{|c|}{ Doctor refused trans care } \\
\hline Yes & 15.7 & 8.3 & \multirow{2}{*}{$79.08 * * *$} & 14.2 & 8.0 & \multirow{2}{*}{$65.12 * * *$} & 11.0 & 5.9 & \multirow{2}{*}{$25.69 * * *$} & 14.7 & 6.7 & \multirow{2}{*}{$122.6^{* * *}$} \\
\hline No & 84.3 & 91.7 & & 85.8 & 92.0 & & 89.0 & 94.1 & & 85.3 & 93.3 & \\
\hline \multicolumn{13}{|c|}{ Doctor refused other care } \\
\hline Yes & 5.5 & 2.5 & \multirow{2}{*}{$37.36 * * *$} & 4.3 & 2.7 & \multirow{2}{*}{$12.68 * * *$} & 3.6 & 1.5 & \multirow{2}{*}{$13.25 * * *$} & 4.7 & 2.0 & \multirow{2}{*}{$40.73 * * *$} \\
\hline No & 94.5 & 97.5 & & 95.7 & 97.3 & & 96.4 & 98.5 & & 95.3 & 98.0 & \\
\hline \multicolumn{13}{|c|}{ Doctor asked invasive questions } \\
\hline Yes & 27.9 & 19.1 & \multirow{2}{*}{$61.42 * * *$} & 24.8 & 19.2 & \multirow{2}{*}{$29.59 * * *$} & 22.5 & 14.4 & \multirow{2}{*}{$36.88 * * *$} & 27 & 16.7 & \multirow{2}{*}{$110.25^{* * *}$} \\
\hline No & 72.1 & 80.9 & & 75.2 & 80.8 & & 77.5 & 85.6 & & 73 & 83.3 & \\
\hline \multicolumn{13}{|c|}{ Doctor used abusive language } \\
\hline Yes & 10.2 & 4.2 & \multirow{2}{*}{$86.47 * * *$} & 8.7 & 4.0 & \multirow{2}{*}{$65.44 * * *$} & 6.5 & 1.3 & $176 * * *$ & 9.2 & 3.0 & $12386 * * *$ \\
\hline No & 89.8 & 95.8 & & 91.3 & 96.0 & & 93.5 & 98.7 & $4 / .0^{\cdots+1}$ & 90.8 & 97.0 & $123.80^{2 \cdots *}$ \\
\hline Doctor $\mathrm{p}$ & ive & & & & & & & & & & & \\
\hline Yes & 3.8 & 1.3 & $1464 * * *$ & 3.1 & 1.2 & $3035 * * *$ & 2.2 & 0.6 & $1121 * * *$ & 2.9 & 1.2 & 2717 *** \\
\hline No & 96.2 & 98.7 & 44.04 & 96.9 & 98.8 & 50.55 & 97.8 & 99.4 & 11.31 & 97.1 & 98.8 & $27.1 / 40$ \\
\hline Verbally & are set & & & & & & & & & & & \\
\hline Yes & 12.2 & 5.0 & $10854 * * *$ & 10.6 & 4.7 & $847-7$ & 7.7 & 2.2 & & 11.2 & 3.4 & \\
\hline No & 87.8 & 95.0 & $108.54 \pi$ & 89.4 & 95.3 & 84.72 & 92.3 & 97.8 & $43.57 * \cdots *$ & 88.8 & 96.6 & $166.5 * * *$ \\
\hline Physical & care se & ing & & & & & & & & & & \\
\hline Yes & 1.0 & 0.3 & & 0.9 & 0.2 & & 0.5 & 0.2 & $\mathrm{a}$ & 0.8 & 0.2 & \\
\hline No & 99.0 & 99.7 & $14.37 * \cdots$ & 99.1 & 99.8 & $14.79 * \cdots *$ & 99.5 & 99.8 & & 99.2 & 99.8 & $14.26^{* * *}$ \\
\hline Unwante & ealth $c$ & re sett & & & & & & & & & & \\
\hline Yes & 2.1 & 0.7 & $2610 * * *$ & 1.5 & 0.7 & o $36 * *$ & 1.1 & 0.4 & $551 *$ & 1.6 & 0.6 & $1538 * * *$ \\
\hline No & 97.9 & 99.3 & $20.19 \cdots$ & 98.5 & 99.3 & 9.36 . & 98.9 & 99.6 & $5.51 *$ & 98.4 & 99.4 & $15.38 \cdots+\cdots$ \\
\hline Any neg & & & & & & & & & & & & \\
\hline Yes & 52.6 & 47.4 & $0583 * * *$ & 46.8 & 40.2 & $2761 * * *$ & 44.3 & 33 & $4826 * * *$ & 50.4 & 36.5 & $13471 * * *$ \\
\hline No & 39.2 & 60.8 & & 53.2 & 59.8 & & 55.7 & 67 & 48.20 & 49.6 & 63.5 & \\
\hline
\end{tabular}

${ }^{\mathrm{a}} \mathrm{Had}$ an expected cell count that was too small $(<5)$ for accurate computation of $\chi^{2}$. 